\title{
Building a Regional Music Collection: The Saskatchewan Experience
}

\author{
by Richard Belford, University of Saskatchewan
}

The Saskatchewan Music Collection (SMC) at the University of Saskatchewan preserves and makes accessible the musical heritage of the Province of Saskatchewan. This diverse mixture of folk, country, popular, ethnic (especially Ukrainian), religious, aboriginal, school and community group recordings and sheet music documents the musical and social history of our province as we enter our second century.

Complementing our regular University music collections in the classical and jazz genres, the SMC had its beginnings in the eclectic interests of Neil Richards, a Special Collections Assistant in the U of S Library system. In 1997, Neil convinced then-Library Director Frank Winter to establish a formal collection which would include many of the items Neil had already found in his wanderings around the province. A Task Force was formed to establish parameters, and after the inevitable delays, produced some guidelines. The new collection would be comprehensive in scope, for works with a "Saskatchewan connection": it would include musical material written by, or performed by, or in some cases produced or recorded by, a person with a strong link to the province: for example, being born here, spending a significant amount of their lives here, or living here when the material was written or produced. Thus Joni Mitchell, who attended high school and began her musical career here, Buffy Sainte Marie (born here), and the Rhythm Pals (whose bass player Mike Ferbey was born in Saskatoon) are

all included, as are recordings from the studios of Studio West and Turtle Island Music. In addition, songs written about Saskatchewan, many penned by people who had never set foot in the province but who enjoyed the unique sounds of the names Moose Jaw or Saskatoon, make their way into the SMC.

The emphasis is on sound recordings in any format. Much of the Collection consists of LPs, with several $45 \mathrm{~s}, 78 \mathrm{~s}$, and cassette tapes, and some 10" shellac discs. We even have one 8-track tape, although no player for it yet. And of course, the more modern recordings are largely in $\mathrm{CD}$ format, and the video section (VCR and DVD) is growing.

Sheet music also forms a significant section. There is a growing collection of ephemera: postcards depicting musical events or groups, concert programs, publicity posters and newspaper clippings. Their physical format presents some unique challenges in terms of preservation and display.

The SMC originally shared a crowded space with Special Collections and the University Archives. In 2001, it was transferred to a slightly larger area in the Education /Music Library on campus, located within the building housing both the College of Education and the 

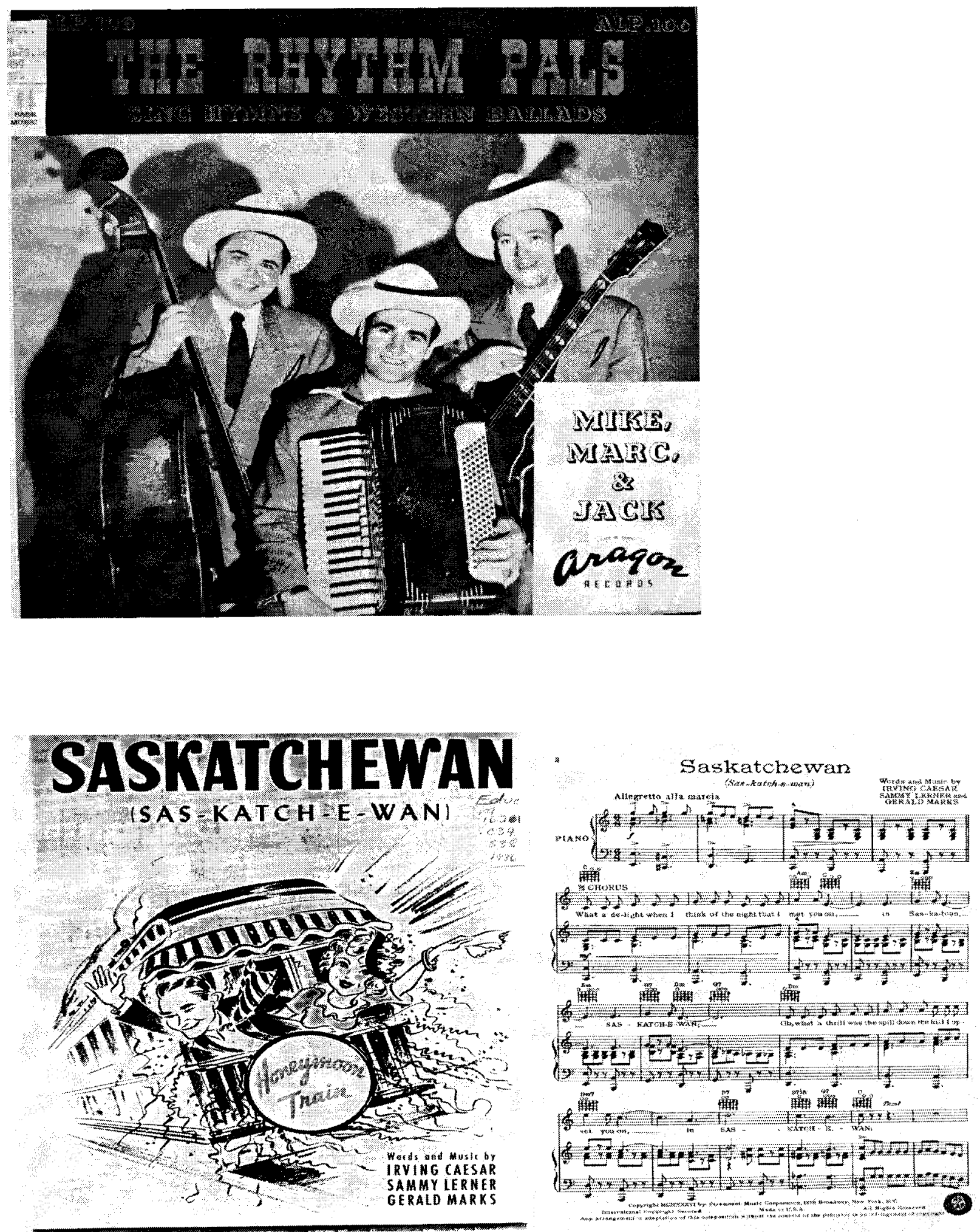
Department of Music. As Neil Richards prepared for retirement in 2002, I was hired as the full-time Music Liaison Librarian and responsibility for the SMC was rolled into the duties of my position.

Our province's historical legacy has been thrown sharply into focus by the succession of centennials celebrated here. The province of Saskatchewan was created in 1905, the City of Saskatoon (home of the U of $S$ ) was established in 1906, and the University of Saskatchewan began in 1907. People are celebrating and reminiscing, and more fully appreciating the achievements of the past. This renewed interest led to a successful application to expand the SMC, and to reconsider the display and housing of the collection. We now have a spacious and attractive area, complete with proper display and playback equipment, and portable display units to take a taste of the SMC around the province.

Musically, the SMC provides evidence of reception of both the music and the artists, the trends and styles of a number of genres, and supports Music Department courses in popular music. It also showcases the music of the First Nations and Métis artists for the increasingly important U of S iPortal, designed to be a central clearing house for information concerning Canada's aboriginal peoples.

Sociologically, this regional collection provides a commentary on the historical, political and cultural structures of Saskatchewan, from clothing and hairstyles -- as evidenced in the richly illustrated album covers -- to our ethnic variety, and through our heritage of musical venues. For example, one of our posters trumpets an appearance of Bobby Gimby (born in Cabri, SK) at the Trianon Ballroom, a popular dance hall in Regina that no longer exists.

Possibly the biggest challenge to acquiring material for the SMC is simply discovering that it exists, and then finding an available copy. Shopping trips to the large mainstream stores will yield many of the more current recordings of local performers, but little of retrospective interest. We also have in Saskatoon some fine second-hand music stores, and these are treasure houses of the older widely-distributed material.

But many of the performers of long ago did not have distribution contracts, and in many cases had simply paid to have their music recorded by the equivalent of a vanity press for sound recordings, and then sold them to their friends and families, or at dances and concerts. These are especially hard to track down, and usually turn up in basements or on family farms. There is a similar pattern developing today: many of the younger artists have sold CDs out of the back of their traveling vans at their concerts for years, rarely moving enough "product" to interest the big distribution chains.

Increasingly, many artists have begun to market their materials on the Internet, with direct website sales accounting for most of their recording revenue. For the artists, it is a practical necessity; for collectors, it is a nightmare! The silver lining has proven to be eBay and other online auction sites, where many unpublicized gems turn up in unlikely places; these may be purchased and shipped anywhere in the world. 
But the single most important source of acquisitions is our donors! Usually accompanied by enthusiastically recounted stories, the obscure treasures often surface as the result of the extensive publicity done for the SMC. CBC Saskatchewan has done three live interviews with musical examples, and one recorded feature; Shaw Cable TV had a story in their rotation for a week; our local newspaper, the Saskatoon Star Phoenix, ran a detailed article; and I have presented papers at CAML conferences and in our U of S Fine Arts Lecture Series and mounted displays at music festivals and awards shows. Each event brought in new donors who hadn't known that the SMC existed, resulting mostly in donations of one and two LPs, but one inquiry turned out to be a gold mine. A retired Saskatoon police officer who had nurtured his hobby of square dance calling by becoming an avid/fanatical record collector, and who was now downsizing his home, offered all of the Saskatchewan material currently stored on a farm in a 25 foot trailer. The collection turned out to contain between 30 and 35 thousand LPs! After two long days of sorting and winnowing, we returned with 291 new titles for the SMC. Consistent with my other donor experiences, the couple who so generously donated these items were warm and entertaining people with a strong interest in Saskatchewan's history, and they have since spread the word to many of their friends.
Support doesn't end with the general public. Many local businesses and organizations, such as the Saskatoon Symphony, the Saskatchewan Country Music Association, the Saskatchewan Recording Industry Association, several radio stations, and many individual artists and groups, have supported us with free advertising and offers of donated materials.

Publicizing the SMC is just one way in which we try to make the Collection more accessible. Each item is fully catalogued and searchable in the $U$ of $S$ Catalogue http:/sundog.usask.ca/, including series access under "Ti = Saskatchewan Music Collection". We currently have a project underway to enhance the catalogue records so that they include biographical information about the performers, photos of the record jacket art, and sound clips or images of the music (subject to copyright restrictions). Our new display units offer easy browsing, with listening facilities close at hand. And future plans include linking many of the other excellent collections in Saskatchewan to create a one-stop shop for research into Saskatchewan's musical heritage.

What started as a private interest has become a provincial treasure, ensuring that future generations of music makers will always have a strong resource to explore the history of Saskatchewan music. 